\title{
AlguMAS OBSERVAÇÕES INTRODUTÓRIAS SOBRE O PRINCÍPIO DE VERITAÇÃO
}

\author{
CÉSAR SCHIRMER DOS SANTOS
}

\begin{abstract}
The truth-making principle is one of the main subjects in contemporary metaphysics, and this paper is an elementar exposition of the main issues of the on-going debate. I will proceed as follows. First, I will expose the basics, including the principle's range, the main kinds of truth-making, the main interpretations of the principle, and some applications. Second, I will expose some technical issues about ontological commitment, reification, necessity, reality, and truth.
\end{abstract}

Keywords: Truth-making; ontology; truth; reality; metaphysics; grounding.

\section{Veritação: o básico}

A literatura recente da área de metafísica vem sendo enriquecida por um amplo e profundo debate sobre aquilo $x$ - o que quer que seja - que torna verdadeira uma frase (ou outro tipo de item de natureza lógico-linguística, como, por exemplo, uma proposição) verdadeira $p$. A intuição que move esse debate é que uma frase não é verdadeira fortuitamente. Em vez disso, uma frase verdadeira é verdadeira por gozar de um certo tipo de vínculo com a realidade, e o estudo desse vínculo é o estudo da veritação, ou truth-making, em inglês. Sendo um tipo de vínculo, a veritação se dá entre dois tipos de vinculados. Por um lado, aquilo que torna uma frase verdadeira é um veritador, produtor de verdade, ou truth-maker, em inglês. Por outro lado, uma frase é um veritado, uma portadora da verdade, ou truth-bearer, em inglês. Considerando essa terminologia, o estudo metafísico da veritação trata da natureza do vínculo metafísico entre veritadores e veritados, produtores de verdade e portadores de verdade.

O estudo da veritação faz parte de uma área de estudos mais ampla, a qual trata das diversas maneiras nas quais uma coisa pode ser uma base ou solo, na realidade, para a proliferação de coisas. Uma coisa pode ser causa de outra - eis o fenômeno metafísico da causalidade. De um agrupamento de coisas pode sobrevir um novo tipo de qualidade ou disposição - eis o fenômeno metafísico da superveniência. A existência de algo pode ser suficiente para que uma frase seja verdadeira - eis o fenômeno metafísico da veritação. Aqui temos três tipos de fenômenos metafísicos, a causalidade, a sobreveniência e a veritação, respectivamente, que formam, em conjunto, o campo de investigação do solo ou base ontológica, ontological ground ou grounding, em inglês (cf. Tahko 2015).

Principia 20(2): 201-214 (2016).

Published by NEL — Epistemology and Logic Research Group, Federal University of Santa Catarina (UFSC), Brazil. 
Portanto, falar em veritação é falar de um tipo de vínculo metafísico no qual algo que faz parte da realidade é suficiente para que uma frase tenha o verdadeiro como valor de verdade. O vínculo de veritação é tal que a mera existência do solo ontológico é suficiente para tornar verdadeira uma frase verdadeira (cf. RodriguezPereyra 2005). Se há o solo ontológico, então a verdade frutifica. O solo ontológico também é necessário para tornar verdadeira uma frase verdadeira. Se não há o solo ontológico, então a verdade não frutifica. Como se explica essa relação entre a coisa veritadora e a frase veritada? Não se trata de um tipo de causalidade. Ou, ao menos, é obscuro como um ente poderia ser causa suficiente de uma propriedade lógicolinguística. Parece mais natural seguir um desses dois caminhos: ou tomar o vínculo de veritação como um tipo primitivo de solo ontológico, ou tomá-lo por um tipo de superveniência. Voltaremos a esse tema em seguida. Seja como for, isto é, seja a veritação um tipo próprio de solo ontológico ou um subtipo de superveniência, o mais plausível é que a veritação não seja fruto da causalidade. Mais razoável é tomar a veritação por um tipo de acarretamento ou corolário - metafísico, não meramente lógico - de certo tipo de vínculo que se estabelece entre algo que se dá no mundo e um item de natureza lógico-linguística.

Não se trata, é claro, de um tipo de acarretamento de natureza lógica. A implicação material, por exemplo, é um tipo de acarretamento lógico, e, como todo tipo de acarretamento lógico, ela só se dá entre itens de natureza lógico-linguística, os quais têm algum valor semântico, como por exemplo a referência ou a verdade. O caso do vínculo de veritação é totalmente diferente, pois se trata de uma relação entre algo sem valor semântico intrínseco e algo que tem algum valor semântico. De modo que a veritação não é um tema da lógica, mas sim um tema da metafísica. Pensando no caso específico, e menos problemático, de uma frase sintética e predicativa verdadeira (em seguida, veremos o tema da veritação com relação aos diversos tipos de frase), o veritador é aquilo que a torna verdadeira. A frase verdadeira "A rosa é vermelha" é verdadeira em virtude da rosa ser vermelha. Ser verdadeiro em virtude de algo não é ser acarretado logicamente, pois se trata de uma relação metafísica entre algo do domínio do real e algo do domínio da linguagem. Se o ente $x$ torna a frase $p$ verdadeira, então a existência de $x$ faz com que $p$ tenha que ser verdadeira, dado que a falsidade de $p$, suposta a existência de $x$, viola o princípio de veritação.

Mais apropriado do que a comparação com a lógica parece ser aproximar o estudo metafísico da veritação da investigação de Quine sobre a natureza dos compromissos ontológicos, pois a proposta de investigar o vínculo de veritação trata dos comprometimentos com o que há na realidade que estão pressupostos no fato de uma frase ser verdadeira. Quine segue o caminho entre o que há e a verdade no sentido oposto da investigação sobre a veritação, pois parte de certas teorias verdadeiras para estabelecer que certos tipos de entes são valores de variáveis dessas teorias (cf. Quine 2011). Mas, claramente, tanto os investigadores da veritação quanto Quine estão às voltas 
com a questão do compromisso ontológico. A proposta da veritação diz o mesmo que Quine sobre os compromissos ontológicos? Ou se trata de propostas rivais com respeito ao mesmo assunto?

Vejamos o caso da frase "A rosa é vermelha". Vamos estipular que esta frase é verdadeira, ao menos para os fins da comparação entre a proposta da veritação e a teoria de Quine. Sendo Quine um nominalista, seus compromissos ontológicos são com indivíduos. Assim sendo, um discurso que inclua a frase em tela envolve um compromisso com a existência de uma certa rosa. Podemos dizer que essa rosa é suficiente para tornar a frase em estudo verdadeira? Na verdade não podemos dizer isso, ou ao menos não podemos dizer isso sem apresentar maiores esclarecimentos, pois, ao menos em algumas metafísicas, poderíamos dizer que a mesma rosa poderia não ter a propriedade de ser vermelha e ter a propriedade de ser branca, por exemplo - Leibniz diria que as propriedades individuam uma substância individual, Arnauld discordaria (cf. Leibniz 2004). Assim sendo, não segue, ou ao menos não segue sem maiores explicações, que a rosa é suficiente, por si só, para tornar a frase verdadeira. Eis, então, que há uma importante diferença entre a investigação da veritação e a proposta de Quine com respeito aos compromissos ontológicos, pois para falar sobre compromisso ontológico basta falar sobre o que há, mas para falar sobre veritação é preciso articular uma teoria sobre como a realidade, incluindo existência e propriedades, torna verdadeira uma frase. São dois assuntos diferentes.

Mas, se a rosa por si só não é suficiente para tornar verdadeira a frase "A rosa é vermelha", o que seria? Claramente, a propriedade da vermelhidão também não seria, pois esse universal poderia (ao menos em algumas metafísicas) não estar sendo instanciada por essa rosa. Sendo assim, a proposta de investigação dos veritadores está comprometida com outros tipos de itens ontológicos, diferentes dos indivíduos e das propriedades. Com isso, chegamos a outra diferença em relação à teoria de Quine, pois na ontologia de Quine itens ontológicos diferentes de indivíduos e propriedades são exóticos. São dois os tipos de itens apontados pelos teóricos da veritação. Por um lado, Armstrong diria que o que torna verdadeira a frase "A rosa é vermelha" é o estado de coisas da rosa ser vermelha (cf. Armstrong 1997). Não custa salientar que estados de coisas são categorias ontológicas exóticas, para Quine. Por outro lado, Mulligan, Simons e Smith defendem que o veritador é o tropo — isto é, a propriedade singular e exclusiva — da vermelhidão da rosa (cf. Mulligan, Simons, e Smith 1984). E, novamente, chegamos a uma categoria ontológica exótica para Quine.

Fazendo um balanço parcial do que alcançamos até agora, nós fizemos duas coisas. Primeiro, diferenciamos o que está em jogo na investigação dos veritadores daquilo que diz respeito às relações de acarretamento estritamente lógico-linguísticas, pois essas dizem respeito a relações entre propriedades semânticas, como a verdade, não à relação entre existência e verdade. Segundo, esclarecemos que a investigação sobre a veritação se relaciona ao estudo de Quine sobre os compromissos ontológicos, 
mas, quanto a isso, deixamos claro duas coisas. Primeiro, que se trata de assuntos diferentes. Segundo, que as principais teorias da veritação estão comprometidas, na metaontologia, com categorias ontológicas que Quine não aceita, como estados de coisas e tropos.

\section{Escopo da teoria}

Uma questão saliente aos investigadores da veritação é o alcance da teoria. A principal motivação para defender uma teoria da veritação é buscar uma ancoragem em solo ontológico - isto é, na realidade - para as frases verdadeiras, dado que essas frases não são verdadeiras por meros caprichos individuais ou coletivos dos falantes. No entanto, há ao menos quatro tipos de frases verdadeiras que problematizam a proposta. São eles as verdades necessárias, as verdades analíticas, as frases existenciais negativas verdadeiras e as frases verdadeiras sobre o passado (e também sobre o futuro, mas podemos deixar esse assunto para outra oportunidade sem prejuízo para nossa exposição, ou podemos simplesmente considerar que frases sobre o futuro não têm de valor de verdade, como sugere Aristóteles — cf. Aristóteles 2013; Barbosa Filho 1999).

Considere uma verdade necessária, como por exemplo que $2+2=4$. Parece não ser nem um pouco frutífero investigar o que torna essa frase verdadeira, pois sabemos que a frase não pode ser falsa, dada que da sua falsidade seguem contradições.

Agora considere uma verdade analítica, como por exemplo que uma garota solteira é uma garota que nunca se casou. Novamente, não parece produtivo buscar pelo veritador dessa frase, pois se trata de uma verdade por convenção, independente de como o mundo é (cf. Rodriguez-Pereyra 2005, p.21, n. 7). O valor de verdade da frase "Solteiros não são casados" pode mudar, não por ter mudado o veritador, mas sim por mudar a definição de solteirice, ou casamento. Logo, a veritação não tem nada de importante a dizer sobre a verdade de frases analíticas. Como no caso das frases analíticas o "capricho" coletivo é legítimo e suficiente para a verdade, não há muito a se aprender investigando seus veritadores.

Um caso muito mais problemático diz respeito às frases existenciais negativas verdadeiras, como por exemplo "Papai Noel não existe". Considere, a la Armstrong, que essa frase é tornada verdadeira pelo estado de coisas da inexistência do Papai Noel. Essa resposta tem dois problemas. Primeiro, não é nem um pouco esclarecedora. Segundo, é misteriosa, pois o que seria algo como o estado de coisas da inexistência de alguma coisa? Que tipo de item ontológico é, positivamente, a inexistência de alguma coisa? Simplesmente não sabemos. Além disso, é simplesmente um erro lidar com o problema metafísico da inexistência de uma coisa apontando para a existência de outra coisa (cf. Melia 2005, p.69). Outra proposta é tomar um enunciado exis- 
tencial negativo verdadeiro como veritado não por algo positivo, mas pela falta de contraexemplo (cf. Liggins 2005, p.106). No entanto, ou isso quer dizer que nem toda verdade requer veritador, ou isso quer dizer, misteriosamente, que uma verdade negativa é veritada por uma presença negativa. Mas, como? O mistério é tamanho que quiçá caiba concordar com Strawson, para quem algo como um fato negativo é "uma não-presença ubíqua" (cf. Strawson 1950).

Outro caso problemático diz respeito às verdades sobre o passado. É verdade que Napoleão perdeu a batalha de Waterloo. Segundo a proposta da veritação, há algo, na realidade, que torna isso verdade. Mas o que seria isso? Um fato passado que existe no presente? Ou um fato passado que existe eternamente?

Esses tipos de casos trazem dificuldades à proposta de investigar a veritação, pois colocam os investigadores em dilemas, ao menos nos casos mais difíceis, como aqueles sobre os enunciados existenciais negativos verdadeiros. O principal dilema é o seguinte: ou o investigador se compromete, na metaontologia, com categorias muitíssimo exóticas, como os fatos negativos, ou restringem o alcance da teoria dos veritadores (cf. Tallant 2009). Nenhum dos lados do dilema é confortável. O primeiro não é confortável por motivos óbvios, o segundo porque restringir o alcance da teoria da veritação parece ir contra a própria motivação para a proposta. Afinal de contas, se algo na realidade torna verdadeira uma frase verdadeira, por que algumas frases verdadeiras não seriam tornadas verdadeiras por algo na realidade?

Uma solução proposta é tratar a veritação não como um tipo primitivo de solo ontológico, mas como um subtipo de superveniência. No slogan de John Bigelow, a verdade sobrevém ao ser, de modo que se um ente $x$ é, então uma frase $p$ é verdadeira, e para que a frase $p$ fosse falsa seria preciso que $x$ não existisse (cf. Bigelow 1988; 2009).

\section{Variedades de veritação}

Há várias versões do princípio de veritação. Na versão mais forte, o princípio diz que há uma entidade veritadora para cada frase verdadeira (cf. Rodriguez-Pereyra 2005). $\mathrm{Na}$ versão mais fraca, a verdade de uma frase verdadeira sobrevém ao que se dá no mundo (cf. Bigelow 1988). O princípio também pode se mostrar tanto de maneira irrestrita quanto de maneira restrita. Há mais de uma maneira de restringir o princípio de veritação, mas as duas principais maneiras de restringi-lo é com respeito ao discurso e com respeito à ontologia. Quanto ao escopo discursivo, o princípio pode ser irrestrito, abrangendo todo e qualquer tipo de frase verdadeira, ou restrito, excluindo ao menos uma classe de frases verdadeiras, seja essa as verdades universais, as verdades analíticas, as frases existenciais negativas verdadeiras etc. Quanto à ontologia, o princípio pode ser irrestrito, aceitando tanto veritadores que existem a la Quine

Principia 20(2): 201-214 (2016). 
quanto veritadores que são mas não existem, a la Meinong, ou o princípio pode tacitamente ou não — ser restrito apenas ao que existe (cf. Daly 2005, pp.85-6).

A versão do princípio de veritação que envolve quantificação meinongiana é bem mais rara, e bem mais poderosa, do que a versão quineana. Na versão meinongiana, há um veritador para cada verdade, mas o veritador pode não existir, o que é conveniente para lidar com verdades sobre a ficção e sobre o passado (cf. p.86).

\section{Compromissos ontológicos}

Há compromisso ontológico quando estabelecemos que uma teoria verdadeira diz algo sobre o que é ou existe. Sendo assim, a noção de compromisso ontológico se mostra enormemente útil, pois alinha a teoria com a ontologia (cf. Liggins 2005, p.105). O princípio de veritação está de acordo com a noção quineana de compromisso ontológico, segundo a qual quem profere a frase $p$ está comprometido com o ente $x$ se a verdade de $p$ acarreta que $x$ é ou existe. No entanto, disso apenas não segue, sem premissas adicionais, que o princípio de veritação precisa estar de acordo com a metaontologia quineana, a qual defende que só há o que existe. Em vez disso, o princípio de veritação pode receber uma leitura meinongiana, de modo que o compromisso ontológico da verdade de $p$ se aplica ao que existe e se amplia ao que não existe, mas é.

Curiosamente, o discurso sobre a ficção não é o exemplo mais apropriado para defender a metaontologia meinongiana como pressuposto do princípio de veritação. Isso porque parece mais adequado, em uma série de casos, tomar uma obra de ficção como o veritador de uma frase verdadeira sobre um personagem de ficção (cf. Kripke 2013). Por exemplo, a frase "Hamlet é um príncipe" é verdadeira sobre a ficção criada por Shakespeare, mas não porque há um príncipe Hamlet inexistente, mas porque há uma obra de ficção existente, e escrita por Shakespeare, que estabelece que Hamlet é, no âmbito da ficção, um príncipe.

Sendo assim, a que vem a proposta de um princípio de veritação movido por uma metaontologia meinongiana? O que se explica com tal proposta? Essa proposta parece adequada para o caso do discurso verdadeiro sobre o passado, o qual diz respeito a entes que não existem, mas são, se veritam as frases verdadeiras (cf. Baron 2015). Se há verdades sobre o passado, e essas verdades disparam o princípio de veritação, então há algo que torna verdadeiras essas verdades. Ersatzismo à parte, o que torna verdadeira uma frase verdadeira sobre o passado não parece ser algo presente e existente, mas sim um algo passado, presentemente inexistente. Esse algo é, mas não existe. Sendo, esse algo passado torna verdadeiras as frases verdadeiras sobre o passado.

Principia 20(2): 201-214 (2016). 


\section{Veritação sem reificação}

Qual a motivação para apresentar o princípio de veritação? Uma resposta seria que o princípio não carece de motivação alguma, pois é óbvio (cf. Armstrong 1989, p.89). No entanto, a dificuldade de aplicação universal do princípio, principalmente no caso de enunciados existenciais negativos verdadeiros, faz com que tenhamos razões para duvidar ao menos da autoevidência do princípio. O que nos leva a buscar outro caminho, um que nos leve à explicitação articulada de uma motivação para aceitar o princípio de veritação. O princípio diz que, se uma frase é verdadeira, então há algo na realidade que a torna verdadeira. Ou seja, o que explica a verdade de uma frase é seu solo, base ou fundamento na realidade. Uma frase é verdadeira porque tem os pés no chão, mas a frase dizer isso ou aquilo não é suficiente para a aterrizagem aqui ou ali. Podemos dizer que a frase $p$ é verdadeira porque $x$ é o caso, mas não podemos dizer que $x$ é o caso porque a frase $p$ é verdadeira. Mas, se é assim, então há uma assimetria entre o discurso, por um lado, e o mundo, por outro lado, pois o mundo torna uma representação verdadeira, mas a representação por si só não faz com que o mundo seja assim ou assado. Essa assimetria é explicada pelo princípio de veritação, pois o mundo é fundamento objetivo da verdade, enquanto a verdade não é sem tal fundamento (cf. Rodriguez-Pereyra 2005).

No entanto, essa motivação para aceitar o princípio de veritação está aberta a uma forte crítica. Ao explicar a assimetria entre o fato de que o mundo torna verdadeira uma frase e o fato de que uma frase, por si só, não torna o mundo tal como nela se representa, se toma a veritação por uma relação entre um veritado, a frase, e um veritador, sendo esse ou um estado de coisas (versão de Armstrong), ou um tropo (versão de Mulligan, Simons e Smith). Mas, ao fazer isso, nossa metaontologia nos obriga a nos comprometermos com categorias ontológicas exóticas - ao menos para o gosto ontológico mais desértico, a la Quine. Melhor seria, diria um crítico, se nos déssemos conta de que pode haver veritação sem que haja veritadores. Se a frase "A rosa é vermelha" é verdadeira, então é porque uma rosa muito específica instancia a qualidade do vermelho, o que nos leva a compromissos ontológicos bem mais modestos, apenas com indivíduos e propriedades, sem nos obrigar a defender que há uma relação entre um estado de coisas (ou um tropo) e uma frase (cf. Hornsby 2005).

\section{Leitura forte, leitura fraca}

O princípio de veritação pode receber ou uma leitura forte, ou uma leitura fraca. Na leitura forte, a veritação é uma relação que requer a existência dos seus relata imediatos, os quais são diferentes do objeto e da propriedade mencionado na frase verdadeira: o tropo ou estado de coisas, no lado do veritador, e a frase, no lado do veritado. Esse tipo de leitura têm o ônus teórico de não ser parcimoniosa, pois 
requer o compromisso metaontológico com instâncias da categoria dos tropos ou da categoria dos estados de coisas. Uma leitura fraca se torna teoricamente atraente se tiver o mesmo poder explicativo, e não tiver esse ônus.

Há dois tipos principais de leituras fracas. Primeiro as leituras da veritação do tipo como-é. Segundo, as leituras da veritação como explicação. Quanto à veritação do tipo como-é, se trata de uma opção à veritação tomada por uma variedade de superveniência, segundo a qual a verdade de $p$ depende de se $x$ é ou não é (cf. Bigelow 2009). Na veritação do tipo como-é, a veritação não se dá porque algo existe, ou não. Em vez disso, a veritação se dá por causa do modo como as coisas são. (Existir é satisfazer uma categoria ontológica, a existência, ser de um jeito é ter certas propriedades, o que se dá satisfazendo-se outra categoria ontológica, podendo até mesmo ser, como defendem os meinongianos, que algo não satisfaça o requisito da existência, mas ainda assim tenha propriedades.) O mundo, enquanto algo que contém a rosa vermelha, torna verdadeira a frase "A rosa é vermelha". O modo como as coisas são verita a frase, de modo que não é a natureza qualitativa da rosa que torna verdadeira a frase, nem a existência da rosa (cf. Beebee e Dodd 2005, p.11; Liggins 2005, p.107). Assim sendo, não é preciso esperar uma relação entre uma frase (o veritado) e uma coisa (o veritador) para que se dê a veritação, de modo que não é preciso um compromisso metaontológico com tropos ou estados de coisas, o que torna menos oneroso esse tipo de leitura fraca.

Outro tipo de leitura fraca toma a veritação por um tipo de explicação. A ideia é que, para cada frase verdadeira, deve haver uma explicação de porque a frase é verdadeira (cf. McFetridge 1990, p.42). Assim sendo, o veritador não é um ente, mas sim uma explicação, o que torna essa leitura pouco onerosa com respeito aos compromissos ontológicos.

Em suma, há duas visões principais sobre o que, exatamente, é o veritador de uma frase. A primeira é teoria fraca da veritação sem entidades especiais fazendo o papel de veritadores. A segunda é a teoria forte, com entidades especiais fazendo o papel de veritadores. A rosa é vermelha, e a frase diz que a rosa é vermelha. Na leitura fraca, a frase é verdadeira porque a rosa, isto é o objeto, é vermelho; alternativamente, a frase é verdadeira porque - eis como as coisas são - a rosa é vermelha. Não é preciso considerar algo além do objeto ou fato para haver veritação, o que significa que a rosa ela mesma é suficiente para a veritação.

$\mathrm{Na}$ leitura forte, é preciso que haja uma entidade além da rosa vermelha que torne verdadeira a frase "A rosa é vermelha". Essa entidade pode ser um estado de coisas, ou um tropo, ou quem sabe até mesmo algo de outra categoria ontológica.

Julian Dodd apresentou um importante argumento contra a leitura forte (cf. Dodd 2002). Suponha que a verdade sobrevém ao ser, e que essa superveniência explique a veritação (cf. Bigelow 1988). Levemos novamente em conta nossa frase verdadeira por estipulação, "A rosa é vermelha". Digamos que, no mundo possível $w_{1}$, a rosa 
seja vermelha, o que verita a frase, e que no mundo possível $w_{2}$ a mesma rosa seja branca, o que falseia a frase. Se o veritador é apenas o objeto, no caso a rosa, então não se pode falar em veritação como superveniência, pois em $w_{2}$ o mesmo objeto que verita a frase em $w_{1}$ falseia a frase. A solução óbvia parece ser considerar o veritador como o objeto (a rosa) e sua respectiva propriedade (vermelhidão em $w_{1}$, brancura em $w_{2}$ ). Mas isso também não resolve o problema, pois não é suficiente para explicar porque a frase é verdadeira em $w_{1}$ e falsa em $w_{2}$. O que falta? Bem, falta, como item ontológico de $w_{1}$, a relação de instanciação da vermelhidão pela rosa. Isto é, falta, na ontologia de $w_{1}$, ao menos uma coisa requerida para haver veritação, a saber um estado de coisas, o ser vermelho da rosa. (A crítica não atinge a leitura do veritador como tropo.) Disso se conclui, contra a leitura forte do princípio de veritação, que a verdade não sobrevém ao ser - a não ser que se enriqueça a ontologia com estados de coisas. Mas disso nada segue contra a leitura fraca, seja na leitura que trata o veritador como o jeito (o como, o qua) da realidade ser seja na leitura que trata o veritador como uma explicação.

Não me parece parcimonioso defender, como o faz Gonzalo Rodriguez-Pereyra (2005), que um veritador é uma entidade à parte. Em suma, o argumento de Rodriguez-Pereyra é o seguinte (cf. Rodriguez-Pereyra 2005, pp.23-5):

1. O veritador de "A rosa é vermelha" é diferente de "A rosa é leve".

2. Assim sendo, temos que ser capazes de identificá-los e quantificar sobre eles.

3. Logo, eles são entidades.

Não vejo como, mesmo aceitando o argumento para o fim do debate, aceitar que as maneiras de ser da rosa têm existência separada da rosa. Nada nesse argumento garante essa conclusão. Em vez disso, o argumento parece garantir uma leitura mais parcimoniosa, segundo a qual são as maneiras de ser da rosa, enquanto propriedades imanentes à rosa, que veritam as frases verdadeiras sobre a rosa (cf. Hornsby 2005, p.40). Além disso, o argumento de Rodriguez-Pereyra nos leva a reificar todo e qualquer estado de coisas que torne verdadeira alguma característica da rosa. Mas isso não pode ser feito sem se violar um princípio básico do realismo, segundo o qual não se deve inferir características da realidade de meras características do discurso (cf. Morris 2005, p.49). De modo que, se os candidatos a veritadores são estados de coisas, tropos e particulares dotados de propriedades, e os dois primeiros canditados são "fortes", a melhor opção é ficar com a alternativa "fraca" dos veritadores como particulares dotados de propriedades.

\section{Realidade e verdade}

Não há como apresentar uma motivação para o princípio de veritação que alcance todas as verdades, pois verdades analíticas, por exemplo, são verdades que não de- 
pendem de como as coisas são. Mas há como apresentar uma motivação que vale ao menos para algumas verdades sintéticas. A motivação, nesse caso, é que a realidade determina a verdade da frase verdadeira. Mais especificamente, e explicando a partir de um exemplo, se é verdade que uma certa rosa é vermelha, então essa rosa, enquanto porção da realidade, e sendo como é, torna verdadeira que a rosa é vermelha.

Caso o princípio de veritação valha para ao menos algumas verdades sintéticas, há consequências filosóficas de dois tipos. Primeiro, a verdade se mostra como um aspecto não primitivo e não bruto da realidade, pois é carente (ao menos nesse caso) de solo ontológico. Segundo, há espaço tanto para leituras realistas quanto para leituras idealistas da veritação, pois realistas dirão que veritadores são independentes da mente, o que será negado por idealistas (cf. Rodriguez-Pereyra 2005, pp.20-1).

\section{Aplicações do princípio de veritação}

O princípio de veritação está sujeito a tantas críticas e restrições que é legítimo perguntar sobre aplicações legítimas que mostrem seu valor de maneira indubitável. Uma aplicação bastante notável pode ser feita por nominalistas. Um nominalista tem uma ontologia muito estrita, na qual só são aceitas coisas que fazem parte da categoria dos indivíduos singulares. Por conta disso, é difícil, para um nominalista, aceitar que possa haver uma única e mesma propriedade partilhada por dois indivíduos diferentes, pois isso nos faria quantificar sobre propriedades, o que conta como compromisso ontológico com propriedades. A dificuldade é tal que alguns nominalistas defendem que não há propriedade alguma, logo não há propriedades partilhadas, por mais que indivíduos distintos se comportem de maneira semelhante e pareçam semelhantes (cf. Martin e Heil 1999).

No entanto, o princípio de veritação abre caminho para que um nominalista reconheça que dois indivíduos partilhem uma mesma propriedade sem se comprometer ontologicamente com propriedades. Se é verdade que o indivíduo $a$ tem a propriedade $F$ e é verdade que o indivíduo $b$ tem a propriedade $F$, disso segue que $a$ e $b$ têm uma propriedade em comum sem que o nominalista quantifique, em momento algum, sobre propriedades. Em nenhum momento, o nominalista tem que se comprometer com propriedades, pois o nominalista tem que se comprometer apenas com os indivíduos $a$ e $b$, sendo como são, isso é sendo $F$, para que haja o veritador de "a é F" e "b é F" (cf. Melia 2005, p.76).

Mas, desse uso do princípio de veritação não segue que o nominalista precisa se comprometer ontologicamente com entidades que tornem verdadeiras as frases verdadeiras? Isso seria péssimo para o nominalista. No entanto, há uma solução geral, a qual permite o uso do princípio de veritação sem o compromisso ontológico com

Principia 20(2): 201-214 (2016). 
veritadores. Essa solução envolve a interpretação de " $x$ verita $p$ " como um operador, não como um predicado (cf. Melia 2005, pp.78-81).

É comum que se interprete o vínculo entre o veritador e a frase veritada como uma relação, a qual requer a existência dos relata. Se assim for, isto é, se $x$ veritar $p$, então há uma frase $p$ que é veritada por $x$, e há um $x$, sendo esse um estado de coisas, ou um tropo, que verita $p$. Essa interpretação toma veritar por um predicado com dois slots, da forma verita $(x, p)$, requerendo um ente $x$ e uma frase $p$ como seus argumentos. No entanto, essa não parece ser a melhor interpretação do vínculo de veritação, pois há evidências em favor da interpretação de " $x$ verita $p$ " como um operador, ou conetivo não-verofuncional. Há conetivos verofuncionais, por exemplo o "e", o "ou", o "não" e o "se ... então" da lógica de primeira ordem. Esses conetivos exigem, como argumentos, sentenças ou representações de outro tipo capazes de receber um valor de verdade, e dão como output um valor de verdade. Outros conetivos, no entanto, recebem como argumento sentenças ou outros portadores de verdade, mas não dão como output um valor de verdade. Um caso é o operador de necessidade da lógica modal. " $\square p$ " quer dizer "Necessariamente, $p$ ", mas não quer dizer "Necessariamente, a frase ' $p$ ' é verdadeira" (cf. Melia 2005, p.79). O mesmo podemos dizer de um operador da lógica temporal, como Pas(p), o qual quer dizer que foi o caso que $p$, não que foi o caso que $p$ é verdadeiro.

Sendo " $x$ verita $p$ " um operador não-verofuncional, quais são os compromissos ontológicos de quem diz que os objetos $a$ e $b$ têm a mesma propriedade $F$ ? Se quem diz isso for um nominalista, o compromisso ontológico com os indivíduos $a$ e $b$ é suficiente, pois se é verdade que $a$ tem a propriedade $F$ e é verdade que $b$ tem a propriedade $F$, então é verdade que ambos são $F$. Esse nominalista pode usar o princípio de veritação sem se comprometer com estados de coisas ou tropos, pois para que o conetivo ou operador " $x$ torna verdade que $p$ " funcione não é preciso que haja uma entidade $x$, seja esse um estado de coisas ou um tropo, que flanqueie uma relação. Basta, no exemplo generalizável em análise, que os indivíduos $a$ e $b$ sejam $F$. Com isso chegamos a uma situação na qual usamos o princípio de veritação sem nos comprometermos ontologicamente com veritadores.

\section{Veritação e metafísica}

Um metafísico que emprega o princípio de veritação defende que verdades têm fundamento na realidade. É claro, então, que a metafísica ela mesma, enquanto teoria sobre como a realidade é, nos seus traços mais gerais (cf. Moore 2012), é um pressuposto fundamental para a aplicação do princípio. E como é a realidade? Parece razoável supor que uma ontologia restritiva quanto ao que há torna mais raros os veritadores, e uma ontologia mais exuberante os inflaciona. É preciso encontrar um 
equilíbrio, mantendo, por um lado, uma visão que tenha o máximo de virtudes teóricas, como a parcimônia e o poder explicativo, e, por outro lado, o estoque requerido de categorias de veritadores para os tipos de frases que normalmente consideramos verdadeiras, sejam essas sintéticas ou analíticas, predicativas ou existenciais, positivas ou negativas.

Talvez um ponto de partida seja concordar, em parte, com David Lewis, aceitando dois aspectos do ser, o aspecto existencial e o aspecto qualitativo/disposicional: "Quero construir 'ser' amplamente, cobrindo não apenas se as coisas são, mas também como as coisas são" (Lewis 1992, p.218); mas rejeitando, contudo, seu realismo modal, pois colocar no reino do ser uma infinidade de mundos possíveis pode ser ótimo para explicar várias coisas, mas não é nem um pouco parcimonioso (cf. Lewis 1986). A verdade sobrevém ao que é no mundo atual, sendo como é, isto é tendo cada objeto que há as qualidades e disposições que têm (cf. Martin e Heil 1999).

Conhecemos muito bem as razões que levam Lewis a postular outros mundos. Isso seria requerido, na visão de Lewis, para dar fundamento ao discurso sobre o que é possível e sobre o que é necessário. Do ponto de vista de Lewis, o mundo atual é suficiente para veritar ou falsear que baleias são mamíferos, mas não é suficiente para veritar ou falsear que possivelmente/necessariamente baleias são mamíferos. Outros mundos seriam requeridos para veritar ou falsear modalidades. Mas não é o caso que, ao investigar as baleias do nosso mundo, descobrimos que elas podem/devem ser classificadas de uma certa maneira? E o que mais investigaríamos, além das baleias do nosso mundo? Usa-se a metáfora da distância entre mundos possíveis, mas nem sempre presta-se atenção ao fato que essa "distância" não é como a distância entre duas cidades, pois se trata de uma "distância" que é mensurada olhando apenas para o que há no mundo atual, o que é adequado do ponto de vista da metodologia, e deve restringir os tipos de entes a serem postulados (cf. Martin e Heil 1999, p.39).

Se o discurso sobre modalidades é legítimo, então o mundo atual é suficiente para veritá-lo, e esse discurso é legítimo. Cabe, então, que investiguemos com mais afinco nosso mundo, para ver bem o que verita o discurso modal. O que torna verdadeiro que necessariamente sou humano? O fato (do mundo atual) que eu sou eu mesmo, sendo como sou. O que torna verdadeiro que pode haver um enorme terremoto em San Francisco? O fato (do mundo atual) que as placas tectônicas estão em tensão crescente naquela região.

Mutatis mutandis, o mesmo vale para o discurso sobre o passado e o futuro. $\mathrm{O}$ discurso sobre o futuro talvez não seja nem verdadeiro, nem falso (cf. Aristóteles 2013; Barbosa Filho 1999). Se for assim, e eu suspeito que é, então o discurso sobre o futuro não carece de veritadores. O discurso sobre o passado é bem diferente, pois sua verdade é pressuposta pela história e pela memória. O que há e como o mundo é torna verdadeiro que Napoleão perdeu a batalha de Waterloo? Um presentista, ao reduzir o ser ao que existe agora, está duplamente impedido de dizer que sim, seja 
por reduzir o ser à existência, seja por reduzir a ontologia à existência no presente. Um presentista é um teórico-A do tempo, e a teoria-B do tempo é famosa por poder dizer que sim, pois Napoleão seria tão real quanto nós. Essa resposta, no entanto, parece tão pouco crível quanto a de Lewis, pois povoa a realidade com entes demais. Outros teóricos-A poderiam seguir dois caminhos. Primeiro, adotar um realismo fora do padrão, e defender que a própria realidade, tomada absolutamente, se apresenta fragmentada, havendo conflito entre o fragmento da realidade que contém Napoleão e o fragmento da realidade que contém a nós contemporâneos, sendo, no entanto, fato que os dois fragmentos fazem parte, com igual direito, da mesma realidade (cf. Fine 2006; Hofweber 2015, pp.483-9). Outro caminho seria distinguir, a la Meinong, entre o que existe no presente e o que houve no passado, sendo que o que houve no passado é real, mas não é existente (cf. Baron 2015).

\section{Fundamentação e necessitação}

Um veritador torna verdadeira uma frase verdadeira. Que tipo de operação é essa? Uma interpretação usual é que o veritador necessita a verdade da frase, de modo que se há o veritador, então é necessário que a frase seja verdadeira. Isso não quer dizer, contudo, que seja suficiente, para explicar a veritação, tomá-la por um tipo de necessidade, pois há uma diferença fundamental entre veritação e necessidade. Uma necessidade é tal que ela se segue de qualquer coisa: se Shakira está de pés descalços, então $2+2=4$. Mas não, os pés descalços de Shakira não tornam verdadeiro que $2+2=4$, pois não há uma relação constitutiva entre os pés descalços de Shakira e o fato que $2+2=4$ (cf. Melia 2005, p.82).

Para haver veritação, é preciso que $x$ seja um solo ontológico de $p$ tal que tenha uma relação de constituição metafísica com $p$. E isso pode ser lido de maneira deflacionária, sem que aceitemos o realismo modal de Lewis ou a inflação de eventos dos téoricos-B. Tudo o que precisamos é de uma metafísica suficientemente rica, e a temos no nosso mundo atual.

\section{Referências}

Aristóteles. 2013. Da interpretação. Traduzido por José Veríssimo Teixeira da Mata. São Paulo: Editora UNESP.

Armstrong, D. M. 1989. Universals: an opiniated introduction. Boulder: Westview Press.

- 1997. A world of states of affairs. Cambridge: Cambridge University Press.

Barbosa Filho, B. 1999. Saber, fazer e tempo: uma nota sobre Aristóteles. In: E. da R. Marques;

E. M. Rocha; L. Levy; L. C. Pereira; M. A. Gleizer; U. Pinheiro (eds.) Verdade, conhecimento e ação: ensaios em homenagem a Guido Antônio de Almeida e Raul Landim Filho, p. 15-24. São Paulo: Loyola.

Baron, S. 2015. Tensed Truthmaker Theory. Erkenntnis 80: 923-944.

Principia 20(2): 201-214 (2016). 
Beebee, H.; Dodd, J. 2005. Introduction. In: H. Beebee; J. Dodd (eds.) Truthmakers: the contemporary debate, p. 1-16. Oxford: Oxford University Press.

Bigelow, J. 1988. The reality of numbers: a phisicalist's philosophy of mathematics. Oxford: Oxford University Press.

- 2009. Truthmakers and truthbearers. In: The Routledge companion to metaphysics, p. 389-400. London: Routledge.

Daly, C. 2005. So where's the explanation? In: H. Beebee; J. Dodd (eds.) Truthmakers: the contemporary debate, p.85-103. Oxford: Oxford University Press.

Dodd, J. 2002. Is truth supervenient on being. Proceedings of the Aristotelian Society 102: 69-86.

Fine, K. 2006. The reality of tense. Synthese 150(3): 399-414.

Hofweber, T. 2015. The place of subjects in the metaphysics of material objects. Dialectica 69(4): 473-490.

Hornsby, J. 2005. Truth without truthmaking entities. In: H. Beebee; J. Dodd (eds.) Truthmakers: the contemporary debate, p.33-48. Oxford: Oxford University Press.

Kripke, S. A. 2013. Reference and existence: the John Locke lectures. Oxford: Oxford Univ. Press.

Leibniz, G. W. 2004. Correspondencia con Arnauld. Traduzido por Vicente P. Quintero. Buenos Aires: Losada.

Lewis, D. 1986. On the plurality of worlds. Malden, MA: Blackwell.

- 1992. Armstrong on combinatorial possibility. Australasian Journal of Philosophy 70: 211-224.

Liggins, D. 2005. Truthmakers and explanation. In: H. Beebee; J. Dodd (eds.) Truthmakers: the contemporary debate, p.105-115. Oxford: Oxford University Press.

Martin, C. B.; Heil, J. 1999. The ontological turn. Midwest Studies In Philosophy 23(1): 34-60.

McFetridge, I. 1990. Truth, correspondence, explanation and knowledge. In: Logical necessity and other essays. London: Aristotelian Society.

Melia, J. 2005. Truthmaking without truthmakers.In: H. Beebee; J. Dodd (eds.) Truthmakers: the contemporary debate, p.67-84. Oxford: Oxford University Press.

Moore, A. W. 2012. The evolution of modern metaphysics: making sense of things. Cambridge: Cambridge University Press.

Morris, M. 2005. Realism beyond correspondence.In: H. Beebee; J. Dodd (eds.) Truthmakers: the contemporary debate, p.49-66. Oxford: Oxford University Press.

Mulligan, K.; Simons, P.; Smith, B. 1984. Truth-Makers. Philosophy and Phenomenological Research 44(3): 287-321.

Quine, W. V. O. 2011. Sobre o que há. In: De um ponto de vista lógico: nove ensaios lógicofilosóficos, p. 11-36. Traduzido por Antonio Ianni Segatto. São Paulo: Editora UNESP.

Rodriguez-Pereyra, G. 2005. Why Truthmakers. In: H. Beebee; J. Dodd (eds.) Truthmakers: the contemporary debate, p.17-32. Oxford: Oxford University Press.

Strawson, P. F. 1950. Truth. Proceedings of the Aristotelian Society 24: 129-156.

Tahko, T. E. 2015. An introduction to metametaphysics. Cambridge: Cambridge Univ. Press.

Tallant, J. 2009. Presentism and Truth-making. Erkenntnis 71(3): 407-416.

CÉSAR SCHIRMER DOS SANTOS

Departamento de Filosofia

Universidade Federal de Santa Maria

cesar.santos@ufsm.br

Principia 20(2): 201-214 (2016). 